\title{
THE CONTINENTAL DRIFT
}

\author{
I've been listening \\ and I think I get it. In the beginning \\ we were all close, shared the ground \\ cover, the oak and the ivy together, and the palm, \\ apples growing with oranges on one hill, the same. \\ Elephants would roam America, \\ ostriches would settle in France.
}

But we let go.

Whether it was like quickie divorce

or a file of unanswered letters, unanswerable letters,

or the ocean pleading its special case

to each soft, reliable coast,

we moved apart.

Africa kept the elephants. We got

the lessons of the oak.

Still it is obvious

how the shapes fit: how any map teases.

I try to read things into it. I try to figure

the message of the Alleghenies, the mottled

America that comes to the edge of the Midwest

and freezes:

where everything is portioned and nothing looks casual, where there is nothing to stop it until the Rockies. 